\title{
Vector-borne diseases in a warmer world: Will they stay or will they go?
}

\author{
Robert Bergquist, ${ }^{1}$ Anna-Sofie Stensgaard, ${ }^{2}$ Laura Rinaldi ${ }^{3}$ \\ ${ }^{1}$ Ingerod, Brastad, Sweden; ${ }^{2}$ Center for Macroecology, Evolution and Climate, Natural History Museum of \\ Denmark, University of Copenhagen, Copenhagen, Denmark; ${ }^{3}$ Department of Veterinary Medicine and \\ Animal Production, University of Naples Federico II, Naples, Italy
}

Meteorological variables, in particular temperature, humidity, water bodies and moisture, govern the distribution of vector-borne diseases (VBDs) through their combined effect on the survival, movement and reproduction of the vector. Temperature is also critical for the maturation of parasite developmental stages inside the vector. Many VBDs are specific, both with respect to the intermediate and the definitive host, while others are zoonotic and thus capable of creating pathogen reservoirs in various animals. Consequently, the VBDs do not only threaten humans but are an even greater hazard for domestic and wild animals.

Climate change (CC), ecological changes (land use and land cover), socio-economic factors, globalization and the development of drug resistance, are all drivers of the VBD scenario. The root cause of the difficulties in unravelling the intricacies of the vector/pathogen/environment triad reside in the multiplicity of dynamic interactions possible. However, the study of VBD distributions in time and space is supported by an array of approaches, such as satellite-generated data, modelling, spatial statistics and geographical information systems (GIS), research activities that constitute major foci in the papers published by Geospatial Health. A central factor is how they might change over the next decades; importantly, how do we anticipate CC to affect the VBD patterns as known today? Indeed, for the majority of the known VBDs, it is currently unclear whether range shifts, contractions or expansions will be the most likely future outcomes. Numerous studies suggest that distributions as well as phenology have already been affected for a wide range of organisms across the globe as the vectors attempt to track their climatic optima. The scientific debate about potential health outcomes remains polarized due to the multifactorial nature of the VBDs, the complex socioecological context in which they participate and the convoluted life cycles needed to support them. Naturally, anticipated consequences vary along with vector species and pathogens, the spatiotemporal scale of investigation and the methodology applied,

Correspondence: Robert Bergquist, Ingerod, Brastad, Sweden.

E-mail: editor@geospatialhealth.net

Key words: Vector-borne diseases; Warm; Climate.

Received for publication: 18 April 2018.

Accepted for publication: 19 April 2018.

CCopyright R. Bergquist et al., 2018

Licensee PAGEPress, Italy

Geospatial Health 2018; 13:699

doi:10.4081/gh.2018.699

This article is distributed under the terms of the Creative Commons Attribution Noncommercial License (CC BY-NC 4.0) which permits any noncommercial use, distribution, and reproduction in any medium, provided the original author(s) and source are credited. aspects that thwart attempts to disentangle climate-mediated changes from other potential causes. Likely scenarios need to be considered as environmental conditions become more suitable for some vectors leading to the introduction of certain pathogens into currently non-endemic areas with immunologically naïve populations. Accurate prediction of potential outcomes play a crucial role in alerting health authorities to future risks. They also have implications for current disease elimination goals.

As much as a quarter of terrestrial vertebrate pathogens of veterinary concern are vector-borne. VBDs in livestock of interest for the World Organization for Animal Health (OIE) include tickborne diseases (e.g., babesiosis, anaplasmosis and various viral encephalitis infections), midge-borne diseases (due to bluetongue and Schmallenberg viruses), mosquito-borne diseases (e.g., those caused by the Rift Valley and West Nile viruses) as well as snailborne diseases such as liver and rumen flukes. The prevalence of Fasciola hepatica in Europe is likely to expand in northern regions by the extension of the transmission season. In addition, outbreaks of acute fasciolosis in sheep farms in the Mediterranean area may have arisen as a possible consequence of CC as shown by Bosco et al. (2015), and the change in the distribution of VBDs affecting pets is well documented by prevalence surveys and forecasting models. Examples include mosquito-borne Dirofilaria in Europe and South America as well as a large number of other VBDs, the spread of which is posing unprecedented challenges to veterinarians and pet owners worldwide (Baneth et al., 2012).

Many human VBDs appear to be spreading into regions in Europe where they previously did not occur. Examples include autochthonous outbreaks of chikungunya in Italy and dengue in France and Croatia following the expansion of the habitat range of the Asian tiger mosquito, Aedes albopictus, while annual epidemics of the Culex mosquito-borne West Nile virus have been reported in eastern and southern Europe since 2010. Old scourges such as malaria, eradicated from Europe in the 1970s, have been discovered during the latest decade in the form of sporadic, locally acquired cases from the Mediterranean parts of Europe, most notably Greece. Other examples include shifts in the range of ticks that act as vectors for Lyme disease and tick-borne encephalitis (TBE) to higher altitudes and more northern latitudes, expansion of the sand fly vectors of leishmaniasis into Italy and a local outbreak of schistosomiasis in Corsica in 2013. Further details are given in a recent review of neglected tropical diseases (NTDs) by Semenza and Suk (2018).

Although CC obviously is an important driving factor, the introduction of new vectors carrying exotic diseases into Europe is primarily facilitated by globalization, in particular trade and travel. However, while scenarios such as CC leading to new VBDs in the North are indeed a cause of concern, populations living at equatorial latitudes continue to suffer the greatest burdens by far, at the same time as resources needed to mitigate the problem are lacking. Nevertheless, there are also positive developments, e.g., 
the hotter and drier conditions in many parts of Africa might reduce the continent's overall incidence of schistosomiasis by decimating the intermediate host snail populations as demonstrated by Stensgaard et al. (2013). However, risk could also increase in the now cooler areas in eastern and southern Africa. With regard to malaria transmission, significant contraction of the global extent of this disease has been observed over the past century although changes have largely been attributed to successful interventions rather than CC (Tatem et al., 2013). On the other hand, a recent study shows a disproportionate future risk of malaria due to $\mathrm{CC}$ between East and West Africa with the highly populated regions in the highlands in East Africa facing future threats (Endo et al., 2017).

The terms threat, hazard and risk are often used as synonyms when discussing the distributions of the NTDs. However, there is an important semantic difference, particularly between the former two and risk, which can be mathematically expressed by a formula that shows risk as a function of the hazard and the population at risk:

$$
R=f\left(H_{e}, P_{v}\right)
$$

where $R$ is the risk, $H$ the hazard (e.g., the simultaneous presence of a case of a specific infection together with its vector) and $P$ the population under threat. $H$ is modulated by environmental variables impacting the vector resulting in various degrees of exposure (e) of humans and animals, while $P$ is influenced by its degree of vulnerability $(v)$, a fairly complex parameter that depends on immunity and general health of the population in question as well as on access to health care and treatment. It is important to remember that hazard is strictly potential, while risk is the probability of this hazard actually occurring. It follows that for populations living in areas characterized as endemic, exposure and infection are close to $100 \%$. It should also be remembered that the degree of risk is a dynamic parameter and risk assessments thus also involve a temporal dimension.

The mathematical approach developed here builds on assessments used for evaluating potential outcomes of natural disasters where the hazard is a natural phenomenon of a given magnitude threatening a given area at a certain time, while the risk is the probability of that hazard exposing populations, property, economic activity, infrastructures, etc. to certain degrees of damage (Shook, 1997). An interesting paper on malaria transmission in Ethiopia based on this approach is offered in the current issue of Geospatial Health (Sewnet et al., 2018).

Future research requires well-orchestrated integration of ideas, skills and know-how seen from different One Health perspectives. The suitability of areas for various vectors can be followed thanks to the availability of 50-year average meteorological datasets at the $1-\mathrm{km}^{2}$ scale, which recently were updated by Fick and Hijmans (2017). The dimensions of these bioclim variables, based on information from tens of thousands of local weather stations all over the world and supported with remotely-sensed data from the moderate-resolution imaging spectroradiometer (MODIS) platform, will continue to be highly useful for risk assessments. However, even if the temperature hazard declines as we move towards the northern arctic circle, or the southern part of the temperate zone in South America, it must be understood that the risk for certain VBDs could rapidly increase also in these regions, should temperatures rise even slightly (Bond et al., 2001). Importantly, as Earth's average temperature has been in a rising trend during the last few decades, VBD transmission patterns could become unstable, a prospect that will require information on the biological variables also at relatively short time periods, and in near real time, to improve predictive modelling.

In conclusion, we acknowledge that studies explicitly examining the impact of $\mathrm{CC}$ with regard to the VBDs remain comparatively few, which contributes to the lack of consensus of the role of CC. This highlights the fact that we are still far from knowing the relative contributions of climate, environmental and socio-economic influences to the changing patterns of VBD risk. Thus, there is a clear need to integrate medical, veterinary, biological, agricultural and social sciences to better understand how these factors are affected by CC. Crucial for this task will be investment not only in systematic surveillance for emerging and re-emerging VBDs for immediate animal and human health purposes, but also commitment to long-term surveillance, including data collection to identify and track impacts of $\mathrm{CC}$ on various vectors and the pathogens they might carry.

\section{References}

Baneth G, Bourdeau P, Bourdoiseau G, Bowman D, Breitschwerdt E, Capelli G, Cardoso L, Dantas-Torres F, Day M, Dedet JP, Dobler G, Ferrer L, Irwin P, Kempf V, Kohn B, Lappin M, Little S, Maggi R, Miró G, Naucke T, Oliva G, Otranto D, Penzhorn B, Pfeffer M, Roura X, Sainz A, Shaw S, Shin S, Solano-Gallego L, Straubinger R, Traub R, Trees A, Truyen U, Demonceau T, Fitzgerald R, Gatti D, Hostetler J, Kilmer B, Krieger K, Mencke N, Mendão C, Mottier L, Pachnicke S, Rees B, Siebert S, Stanneck D, Mingote MT, von Simson C, Weston S, CVBD World Forum, 2012. Vectorborne diseases-constant challenge for practicing veterinarians: recommendations from the CVBD World Forum. Parasit Vectors 5:55.

Bosco A, Rinaldi L, Musella V, Amadesi A, Cringoli G, 2015. Outbreak of acute fasciolosis in sheep farms in a Mediterranean area arising as a possible consequence of climate change. Geospat Health 9:319-24.

Endo N, Yamana T, Eltahir EAB, 2017. Impact of climate change on malaria in Africa: a combined modelling and observational study. Lancet 389:S7.

Fick SE, Hijmans RJ, 2017. Worldclim 2: New 1-km spatial resolution climate surfaces for global land areas. Int $\mathrm{J}$ Clim 37:4302-15.

Semenza JC, Suk JE, 2018. Vector-borne diseases and climate change: a European perspective. FEMS Microbiol Lett 365.

Minale AS, Alemu K, 2018. Mapping malaria risk using geographic information systems and remote sensing: the case of Bahir Dar City, Ethiopia. Geospat Health 13 [In press].

Shook G, 1997. An assessment of disaster risk and its management in Thailand. Disasters 21:77-88.

Stensgaard AS, Utzinger J, Vounatsou P, Hürlimann E, Saarnak CFL, Mubita P, Simoonga C, Kabatereine NB, Tchuem Tchuenté LA, Simoonga C, Rahbek C and Kristensen TK, 2013. Large-scale determinants of intestinal schistosomiasis and intermediate host snail distribution across Africa: does climate matter? Acta Trop 128:378-90.

Tatem AJ, Gething PW, Smith DL, Hay SI, 2013. Urbanization and the global malaria recession. Malaria J 12:133. 